\title{
Humanoid Robots and Human Society
}

\author{
Adam A. Bahishti \\ Department of Physics, College of Science Al-Zulfi, Majmah University, KSA
}

\begin{abstract}
Almost every aspect of modern human life starting from the smartphone to the smart houses you live in has been influenced by science and technology. The field of science and technology has advanced throughout the last few decades. Among those advancements, robots have become significant by managing most of our day-to-day tasks and trying to get close to human lives. As robotics and autonomous systems flourish, human-robot relationships are becoming increasingly important. Recently humanoid robots become interesting as developers trying to model it with human resemblance and equipped with cloud based artificial intelligence. Many ethical issues are under discussion including job loss and fear of machine's thinking power like humans. I believe it should not be a concern that machine will start thinking like human but more important concern should be that humans started thinking like computers. We really need to be natural by preserving our human values and compassion.
\end{abstract}

\section{Robotification}

Robotification is the process in which tasks are performed by machines which were normally supposed to be done by the humans. These machines could be mechanical or software based application and sometimes refer to automation. Robotification is not something that will happen in the future, it's already started many years ago. Just look around for the things you interact which were once done by humans but they are now performed by machines (Allain, 2015). The field of robotics are growing with more applications in various areas of daily life. Researchers are trying to achieve a more precise and grounded understanding of exactly what might be meant by automation (Burgess, Mitchell, \& Highfield, 2018).

Robotification is bringing a completely different kind of society on the way which will challenge the way we feel about machines. Consumer grade robot domination are a long way for general public but already in use through industries automation. For example, sweeper, lawn vacuuming, different kind of vendors, restaurant ordering system, etc. Robots are already offering significant values to households, but developers still have to overcome some technological challenges.

There are many discussions about robot ethics going on that how we should treat robots. As machines getting smarter, it becomes more important that their goals, what they are trying to achieve with their decisions should be closely aligned with human values (McDonald, 2015). Having special laws to govern robots isn't being debated in parliaments/ governing bodies yet, but robots are becoming so smart by learning to interact like humans that it's only a matter of time. For now, it would be difficult to reach any conclusion until these robotic machines are involving in human's life and we need to question our own about suitability of a certain machine.

* Corresponding author email: aabahishti@gmail.com

DOI: https://doi.org/10.21467/ajss.1.1.60-63 
Nevertheless, most popular consumer application of robots would be as housekeepers, performing the chores that free up time for their owners. Few vending machines are already available which might take over the jobs that are repetitive, such as taking orders in restaurants, issuing and returning books in the library. On the other hand, those jobs might shift in maintaining these machines to work in proper order as well as in the robot designing and development industry.

There are lots of concern regarding loosing jobs which robots will take over but in my opinion, there would not be significant job loss. Instead Job will shift toward more educated individual. As mostly human's job can be done by robotic machines leading loss of the job but at the same time to develop, maintain, and operate those machines more job would be created at the backend. Just new job will require more educated and technically skilled individual. Our generation should focus on higher education if they do not want to be affected by technological applications through robotic machines.

Current research into robotics and artificial intelligence (AI) is developing new machines that do not simply perform repetitive tasks, but can learn and adjust behavior to interact with people, working together as partners. These systems are designed to learn and adapt the changing circumstances, interact with society in socially appropriate ways by interpreting human needs and intentions (Merrifield, 2013). In the future, robots may live with humans as long-term companions, however a comparative research between living companion "dog" and non-living companion "robots" shows that people's attitude toward robots is much more negative than towards dogs (Konok, Korcsok, Miklósi, \& Gácsi, 2018). But this attitude may be overcome by recent development of AI robots called Humanoids which is much more resemble to human and can be considered as human's animated avatars. Recent developments lead some to believe that robots can even dream (Lenoir, 2016) as developers trying to design humanoids capable of developing analytical skills, learning ability, communication, and even emotional intelligence.

\section{Humanoid and Society}

A humanoid robot is a robot with its overall appearance based on the human body. Normally humanoids have a torso with a head, two arms and two legs, however some forms of humanoid robots may model only part of the body such as from the waist up. Recent humanoids may have a 'face', with 'eyes' and 'mouth' which can have human expression and might be resemble to some real human. This kind of humanoid robots built to aesthetically resemble a human and known as Androids. Humanoid robots might take over the world and they might look so similar to us that we won't be able to differentiate them from us (Dean, 2016). It is believed that next few decades androids will be completely integrated in society working as shop assistants, bar staff and care workers (Dean, 2016).

Humanoid robotics is an emerging and challenging research field, which has received significant attention during the past years. They are expected to serve as companions and assistants for humans in daily life and as ultimate helpers in man-made and natural disasters. An encouraging spectrum of science and technology has emerged that leads to the ambitious goals for development of highly advanced future humanoid robotics systems endowed with rich and complex sensorimotor capabilities. The inclusion of humanoid robots with Artificial Intelligence, automation in the human society raises ethical questions (Chatila, 2018). This inclusion will allow Humans to fulfill their social needs through social surrogates which are fictional and non-living entities. Despite of few researches which shows social surrogates have beneficial effects on the individual researchers are concern about possible potential to cause psychological harm (Nash, Lea, Davies, \& Yogeeswaran, 2018).

AI Robots are considered helpful for therapy of children with autism because there is an affinity between autistic people and mechanical things (Richardson \& Kathleen, 2017). Further there has been a growing research interest towards utilizing the Robots for Interactive educational purposes through the use of social robotics. Social robots have been and are currently being used in many projects, research initiatives and experiments but we know relatively little about them compared to humans when performing a social task such as teaching. Researcher found several challenges need to be rigorously addressed in order for robotic tutors to be able to feature in education (Fernández-Llamas, Conde, Rodríguez-Lera, Rodríguez-Sedano, \& 
García, 2018; Serholt, 2018). The development of AI robots are entering to a new stage where the focus is placed on interaction with people in their daily environments. With the improvement of more and more complex robots to be used in rehabilitation, heath care, service or other applications, robot-human interaction is a rapidly growing area of research (Durães, Bajo, \& Novais, 2018).

In the future humanoids may live with human as long-term companions specially for old aged peoples to perform routine task and capable to monitor health as well as to call emergency service in case of any odd situation. No wonder, one day, we're going to experience the greatest unemployment crisis in human history. With each successive advance in technology, computers and robots take over more and more responsibilities from humans each day (Brenner, 2017). But same time technology creates other opportunity for us, we should be ready to adopt new technology and its benefit to overcome any such unemployment crisis. Another problem due to the rise of the robots is energy resources as each robot requires plenty of power to operate which might accelerate the unsustainable, insupportable damage to the Earth (Read, 2016). Developers and governments should have a working plan to dump those e-wastes which will come from new technology

Recently a humanoid "Sophia" created by a Hong Kong based company Hanson Robotics is in focus as she can smile mischievously, bats her eyelids, sing and tells a joke. Her appearance so resembles that you could almost mistake her for a human. Sophia said herself as smart input output system in an event "Future Investment Initiative" (FII, 2017) where she also got awarded by the citizenship of Saudi Arabia. This event was highlighted as it was first time that any country announce citizenship for a robot (CNBC, 2017), however what this citizenship actually mean is not clear yet. Even though currently Sophia can respond to peoples question similar to Siri of Apple and Cortana of Microsoft windows with added feature of facial expression and smartness which distinguish her from other humanoids. Hanson Robotics defined it as fusion of artificial intelligence with animation technology. Even though Sophia seems smart in talking and making expressions but how it will be helpful and what other task such humanoids can perform to help human society is still unclear.

\section{Conclusion}

Intelligent robots have been a topic in books and films for decades. Recently AI integration into machine has become so powerful that those stories are no longer seems a science fiction but something that will change our lives very soon. Every technology contains its own merit and demerit. It depends on the user how they wish to utilize it. There are good aspects as well as bad aspects about humanoids being a part of our lives. It is us who should decide on how should we get benefit from it and how to avoid bas aspects. We should be equipped ourselves with higher education to sustain in job crisis situation. Government and companies require to have strategic plan for e-waste management and renewable energy resources for new technologies. I believe that instead of worrying about computer's thinking power through AI, we should worry of human's thinking way towards more look like computer without any human value and compassion.

\section{How to Cite this Article:}

Bahishti, Adam A. (2017, November 30). Humanoid Robots and Human Society. Advanced Journal of Social Science, 1(1), 60-63. https://doi.org/10.21467/ajss.1.1.60-63

\section{References}

Allain, R. (2015). The Robotification of Society is Coming. Retrieved November 25, 2017, from https://www.wired.com/2015/01/robotification-society-coming/

Brenner, L. (2017). Is Artificial Intelligence Good or Bad? Retrieved November 25, 2017, from https://sciencing.com/is-artificial-intelligencegood-or-bad-13400294.html

Burgess, J., Mitchell, P., \& Highfield, T. (2018). Automating the digital everyday: an introduction. Media International Australia, 166(1), 610.

Chatila, R. (2018). Inclusion of Humanoid Robots in Human Society: Ethical Issues. In Humanoid Robotics: A Reference (pp. 1-10). Dordrecht: Springer Netherlands.

CNBC (2017) Interview With The Lifelike Hot Robot Named Sophia. Retrieved November 25, 2017, from https://www.youtube.com/watch?v=S5t6K9iwcdw 
Adam A Bahishti. Adv. J Social Sci.; Vol. 1 Issue 1, pp: 60-63, Nov 2017

Dean, J. (2016). Humanoid robots will "take over the world" and professor warns we won't be able to spot them - Mirror Online. Retrieved November 25, 2017, from http://www.mirror.co.uk/news/uk-news/humanoid-robots-take-over-world-8962442

Durães, D., Bajo, J., \& Novais, P. (2018). Characterize a Human-Robot Interaction: Robot Personal Assistance (pp. 135-147). Springer, Cham. Fernández-Llamas, C., Conde, M. A., Rodríguez-Lera, F. J., Rodríguez-Sedano, F. J., \& García, F. (2018). May I teach you? Students' behavior when lectured by robotic vs. human teachers. Computers in Human Behavior, 80, 460-469.

Future Investment Initiative (2017) Sophia Robot as Speaker. Retrieved November 25, 2017, from http://futureinvestmentinitiative.com/en/speaker/sophia-robot

Konok, V., Korcsok, B., Miklósi, Á., \& Gácsi, M. (2018). Should we love robots? - The most liked qualities of companion dogs and how they can be implemented in social robots. Computers in Human Behavior, 80, 132-142.

Lenoir, F. (2016). Should we build robots that can feel human emotions? Retrieved November 25, 2017, from https://www.weforum.org/agenda/2016/09/can-we-create-robots-with-human-emotions/

McDonald, C. (2015). The Good, The Bad and The Robot: Experts Are Trying to Make Machines Be \&quot;Moral\&quot; Retrieved November 25, 2017, from https://alumni.berkeley.edu/california-magazine/just-in/2015-06-08/good-bad-and-robot-experts-are-trying-makemachines-be-moral

Merrifield, R. (2013). Integrating smart robots into society. Retrieved November 25, 2017, from https://horizonmagazine.eu/article/integrating-smart-robots-society_en.html

Nash, K., Lea, J. M., Davies, T., \& Yogeeswaran, K. (2018). The bionic blues: Robot rejection lowers self-esteem. Computers in Human Behavior, 78, 59-63.

Read, R. (2016). Rise of the robots will harm the Earth as well as humans. Retrieved November 25, 2017, from https://www.theguardian.com/theobserver/2016/mar/27/leters-robots-energy-consuming

Richardson, K., \& Kathleen. (2017). Challenging Sociality? An Anthropology of robots, autism and attachment. Retrieved from https://www.dora.dmu.ac.uk/handle/2086/14788

Serholt, S. (2018). Breakdowns in children's interactions with a robotic tutor: A longitudinal study. Computers in Human Behavior, 81, 250264.

\section{Publish your research article in AIJR journals-}

$\checkmark$ Online Submission and Tracking

$\checkmark$ Peer Reviewed

$\checkmark$ Rapid decision

$\checkmark \quad$ Immediate Publication after acceptance

$\checkmark$ Open Access (Articles freely available online)

$\checkmark$ Retain full copyright of your article.

\section{Submit your article at journals.aijr.in}

